\title{
Korean Academic Librarians’ Recognition of the High Density Book Storage System
}

\author{
Joonsuk Ahn \\ Department of Architecture, Kyonggi University, Suwon, South Korea. \\ Email: jahn@kgu.ac.kr \\ Received November $1^{\text {st }}, 2013$; revised November $25^{\text {th }}, 2013$; accepted December $4^{\text {th }}, 2013$ \\ Copyright @ 2013 Joonsuk Ahn. This is an open access article distributed under the Creative Commons Attribution License, which \\ permits unrestricted use, distribution, and reproduction in any medium, provided the original work is properly cited. In accordance of \\ the Creative Commons Attribution License all Copyrights (C) 2013 are reserved for SCIRP and the owner of the intellectual property \\ Joonsuk Ahn. All Copyright (C) 2013 are guarded by law and by SCIRP as a guardian.
}

\begin{abstract}
Korean academic libraries are facing a serious space shortage problem due to the inability to uphold the rapidly increasing amount of printed materials despite having expanded the number of physical facilities. Data computerization has been considered as a solution to the issue, but deliberation for the High Density Book Storage System has been on the rise because of its impressive method of preserving printed materials in a realistic facility. Despite the different methods of print material storage, Korean academic libraries have largely focused on investing in the least efficient method of compact shelving to solve this issue. It is hypothesized that the misuse of funds on inefficient systems is occurring due to the lack of knowledge about the high-density book storage systems like the Harvard model. In order to propose a realistic solution to the academic library space shortage crisis on a logical basis, it is imperative that a study of academic librarians is conducted to investigate their knowledge on such efficient storage systems.
\end{abstract}

Keywords: Space Shortage Problem; Academic Library Facility; High Density Book Storage; Harvard Model

\section{Introduction}

Korea's rapid economic grown in the 1980s brought enormous spatial expansion to the physical facilities associated with academic libraries. The growth allowed for a new era in establishment of modern Korean academic libraries and fostered a positive impact on collegiate environments nationwide. Beginning in 1955 with only 43 total public and private academic libraries in the entire country, Korea reached a total of 523 facilities in 2009.

More importantly, there was a noticeable increase in book quantity. With 1,297,034 books observed in Korean academic libraries in 1955, the number was registered at 121,479,083 by 2009 [1]. Figure 1 presents the rapid growth curve of printed materials observed in academic libraries from year 1955 to 2009. Table 1 shows the comparison of number of books, academic library facilities, and librarians between 1955 and 2009 in Korea. The total of amount of books had expanded by $9370 \%$, and that increase was almost 8 times faster than the growth of academic library facilities. This exponential growth created a serious space shortage problem for all Korean academic libraries and slowly led to academic environ- ment degradation. Figure 2 represents the problem graphically.

The vastly increasing quantities of printed materials and the library space shortages brought about by it are the biggest problems facing current academic libraries in Korea. Korean academic libraries have been in search of efficient book storage systems to solve the issue. The movable compact shelving unit, also referred to as the 'mobile rack', is widely utilized. Since the adoption of the movable compact shelving system, open access systems have been put in place. The open access system provides higher service quality for its users, but it is limited in space efficiency. The alternative closed access system lacks a user-friendly operating system; however, it has much higher space efficiency at a significantly lower cost. Judging by the cost-benefit tradeoff, the closed access high-density book storage system is the only logical option to resolve the academic libraries' space shortage crisis [2].

The study was projected to assess Korean librarians' understanding of high-density book storage facilities used for academic and research purposes, and identify 
Table 1. Number of academic library facilities, books, and librarians in 1955/2009.

\begin{tabular}{ccc}
\hline Year & 1955 & 2009 \\
\hline Academic & 43 & 523 \\
Libraries & & $121,479,083$ \\
Books & $1,297,034$ & 3686 \\
Librarians & 207 & \\
\hline
\end{tabular}

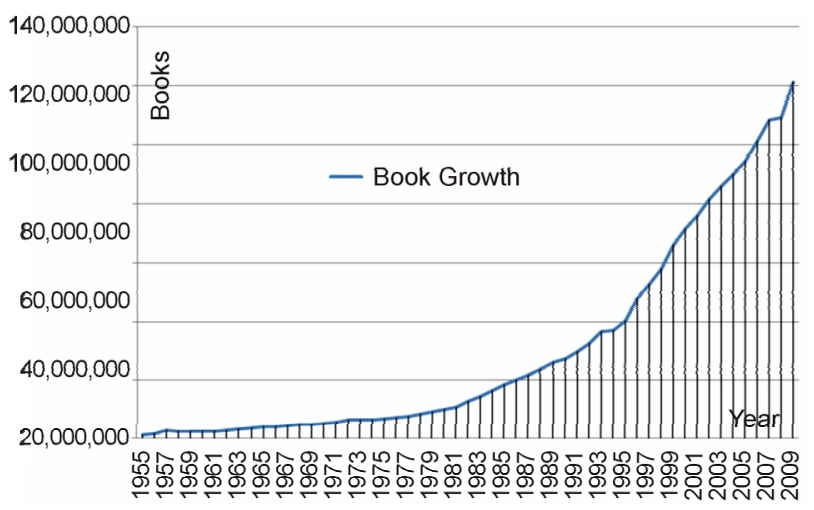

Figure 1. Book accumulation of academic libraries in Korea.

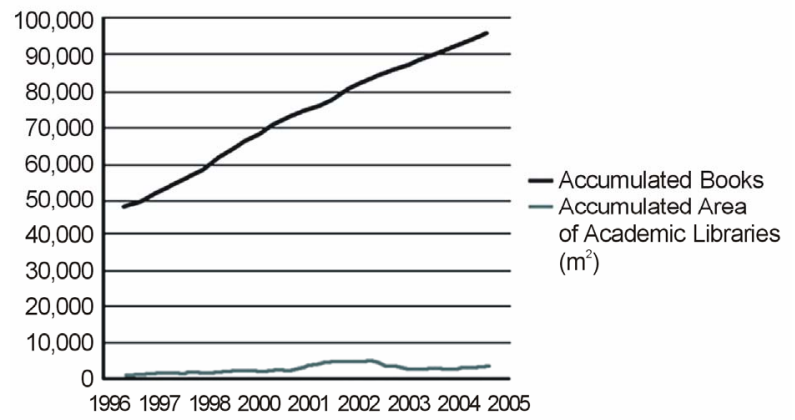

Figure 2. Comparison of book growth to library facility growth [3].

reasons for the lack of establishment of such facilities in Korea. The analysis of the survey responses will serve as a method to further resolve the space shortage crisis in a workable fashion.

\section{High Density Book Storage: Harvard Model}

In the 90's, Harvard began its construction of high density book storages, the "Harvard Model", as an efficient method of preserving low use print materials to serve as the solution for the space shortage problems in academic libraries. The Harvard Model provides extremely high space efficiency at a low cost. The original idea for this system was inspired by the distribution and warehouse industry. This system has spread all over the world and has now become a development standard for book stor- age facilities [4]. Figure 3 shows the shelving system of Harvard Model at Rice University Library Service Center. More than 100 high-density book storage facilities have been built worldwide, 73 of those located just in the United States.

However, it has been found that Korean academic librarians have a definite preference for open access systems and there have not been any Harvard model storages constructed in Korea. An overwhelming majority of librarians continue to prefer expensive library buildings in lieu of low cost storage facilities despite the fact that new open access library facilities will never resolve space shortage problems. Many libraries have installed movable compact shelving units or remodeled their facilities to further accommodate, but these methods only postpone the impacts of the space shortage problem. These libraries inevitably face the same space shortage problems just after a couple of years after the completion of such constructions [5].

\section{Survey Questionnaires \& Evaluation}

Previous surveys show that Korean academic librarians have acknowledged the need for high-density book storage systems in order to resolve space shortage problems. It is proposed that these librarians continue to solely utilize the movable compact shelving system, the mobile rack, with the exception of Sungkyul University's ASRS (Automated storage and retrieval system), because of their lack of understanding of high density book storage systems to make an informed decision on selecting the most efficient storage methods. As librarians are the most important individuals when making decisions on new constructions, remodeling projects, and operation systems of their respective academic libraries, it is important to investigate librarians' understanding of the high density book storage systems and their knowledge of opportunities to resolve space shortage problems.

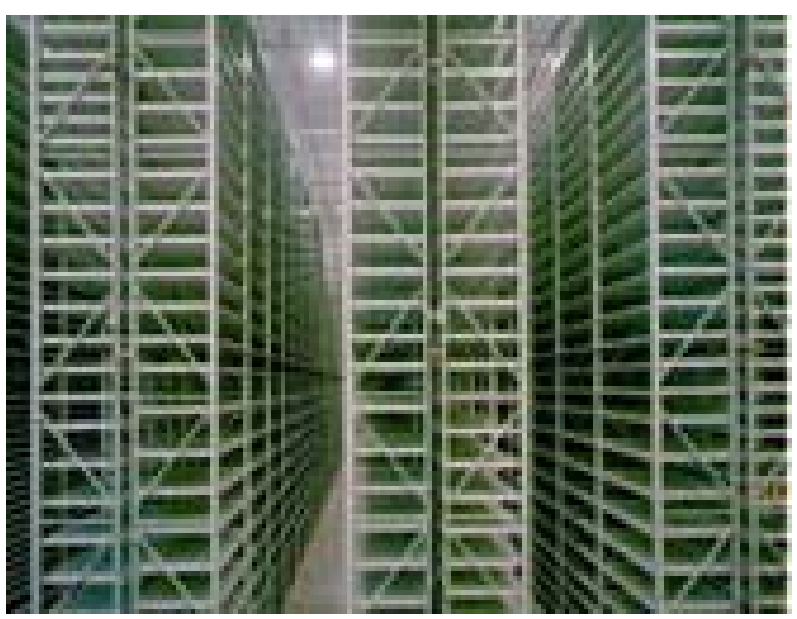

Figure 3. Harvard model storage system at Rice University. 
Questionnaires regarding the issue above were distributed to 463 academic librarians through email. Replies were received through "Google Drive” from 75 librarians at 169 universities in Korea from June 10-16, 2011. The same questionnaires were sent to another 1186 academic librarians at accredited 4-year universities resulting in 182 replies throughout a period from June 26th through June 30th, 2011. The questionnaires resulted in a response rate of $15.5 \%$ and a total of 257 responses.

The survey was comprised by 7 questionnaires as below:

- The necessity for the adoption of high density book storage systems to resolve the space shortage problem

- Knowledge about high density book storage types and operational options

- Critical decision making elements on library facility development

- Preferred methods of obtaining extra space to preserve printed materials

- Application plans for any possible available space

- Plans of developing extra book storage space with the exception of building a new library

- Understanding of cooperative book storage facilities

\subsection{How Effective Do You Believe the High Density Book Storage System Will Be in Reducing the Space Shortage in Your Library?}

The purpose of this question was to measure the librarians' opinion on the efficacy of high-density book storage systems in solving the space shortage issue. Figure 4 represents the replies of this questionnaire. Out of 243 total replies, 159 (53\%) and 100 (41\%) responded that the high-density storage system would be very effective and effective, respectively. Judging from the data that shows a large majority, $94 \%$ of the responses, were positive for the implementation of high-density storage systems, it is concluded that most academic librarians are in favor of introducing this type of method into the nation's library system. From the small percentage of negative responses (1\%), it can be said that there are hardly any opinions opposing high-density book storage systems. Those librarians who responded with a negative attitude towards this type of management system showed a lack of understanding of such systems and an extreme preference for open access management.

\subsection{Choose All High Density Book Storage Types in Which You Are Familiar with the Method of Operation}

This question was posed to librarians so that they would choose all types of high-density book storage systems in which they understood all facility and managing systems in order to investigate their level of understanding for each type of system. The survey result is shown in Figure 5. As expected, the compact shelving system (mobile-rack) received a large sum of 221 votes (91\%) followed by the Automated Storage and Retrieval System (ASRS) with 93 votes (38\%); however, only 4\% of librarians identified as fully understanding the Harvard Model, in addition to a surprising 3\% of librarians which stated that they had no understanding of high density book storages. It is inferred that Sungkyul University's 2010 construction of ASRS models helped in informing librarians about this specific method possibly resulting in the high number of votes for this system. It was unexpected that so many librarians, 34\%, showed a high understanding for the outdated Multi-Tiered Stack Core System, but the result is interpreted as the librarians' informed knowledge about the history of librarians and their shelving systems.

The fact that Korean academic librarians have such limited knowledge about high-density book storages systems like the Harvard model, which has already become a standard in the United States and Europe, shows the librarians' lack of understanding is even far more limited than as previously predicted. The results of this survey show that it is imperative that further knowledge about this type of system is more widely distributed.

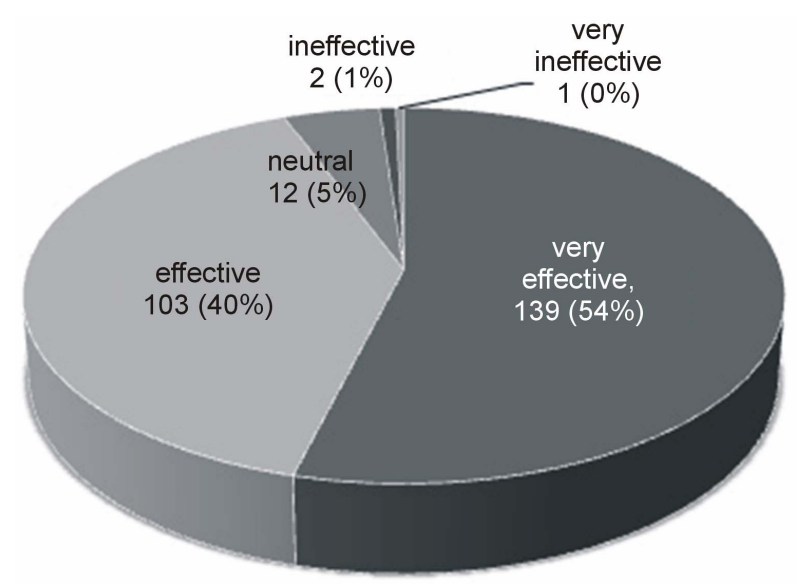

Figure 4. Necessity of high density book storage.

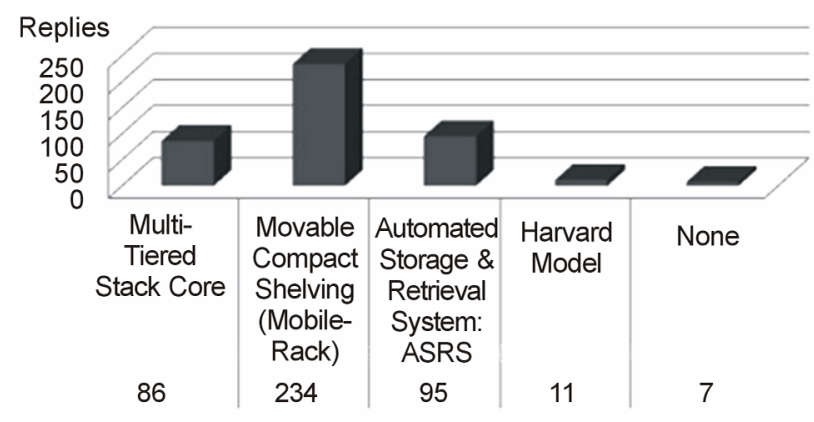

Figure 5. Awareness of high density book storage types. 


\subsection{What Is the Most Critical Element You Consider When Selecting a Book Storage Type?}

The $66 \%$ of librarians replied that the book storage capacity per square footage, therefore space efficiency, was a critical element when selecting a storage type. This result is a strong representation of the magnitude of the academic library space shortage problem alongside the librarians' desire to resolve the issue. It signifies that spatial efficiency, rather than construction cost, should be deemed the highest priority when selecting a storage system. From the results, it can be inferred that librarians would prefer a facility with guaranteed space efficiency even with a trade off with time spent on budget collection compared to a shortsighted facility.

$19 \%$ of the responses chose construction cost as seconding space efficiency in elements to be considered when choosing a storage facility. Difficulties in fulfilling a budget to construct a book storage system pushed opinions to prefer economical and practical facilities. A small minority of the responses chose options such as operational manpower (4\%), operation and maintenance cost (5\%), facility location (6\%), showing that these other alternatives were far less critical compared to establishment cost and space efficiency. Figure 6 shows the replies of this question. The Harvard Model is the most space efficient of the book storage systems with a low operation and maintenance cost needed for manpower in addition to low construction costs. Judging from the responses received from the pool of librarians surveyed, such systems that fully accommodate for all the considerations are the best options that should be introduced into the nation.

\subsection{Which Option Is Best for Securing Extra Library Space? (Under Limited Budget)}

Responses shown in Figure 7 indicated that $40 \%$ of librarians' preferred storage options that are economical and better insure security of budget. However, large opinions showed that librarians still largely believed that at equal costs, they preferred open access to closed access services even if that meant less space efficiency (37\%). It is thought that this is because when the questionnaire was formulated, the survey did not mention that open access storage systems preserved a mere $10 \%$ of what a high density book storage would under the same given square footage. Because librarians lack full understanding of the space efficiency potentials of the highdensity book storage system, they still select the open access storage that matches the traditional library structure at a high percentage. Regardless of construction costs, librarians who supported the open access storage systems $(15 \%)$ were relatively higher than those who

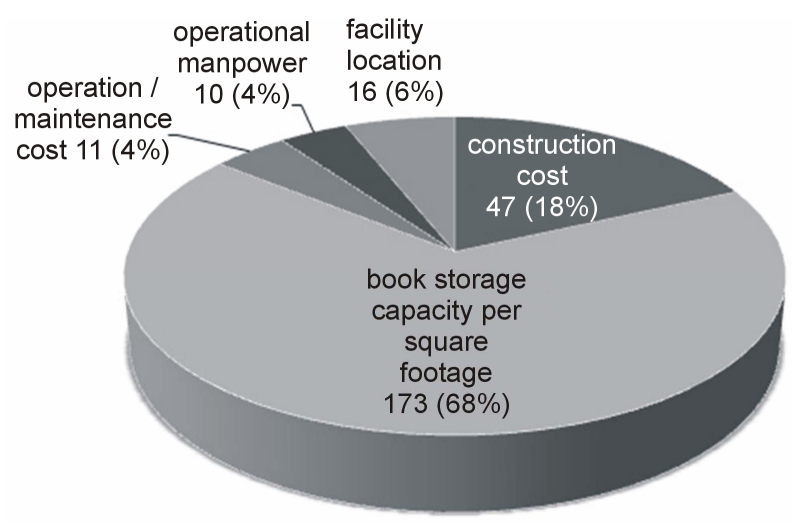

Figure 6. Critical decision element on storage type selection.

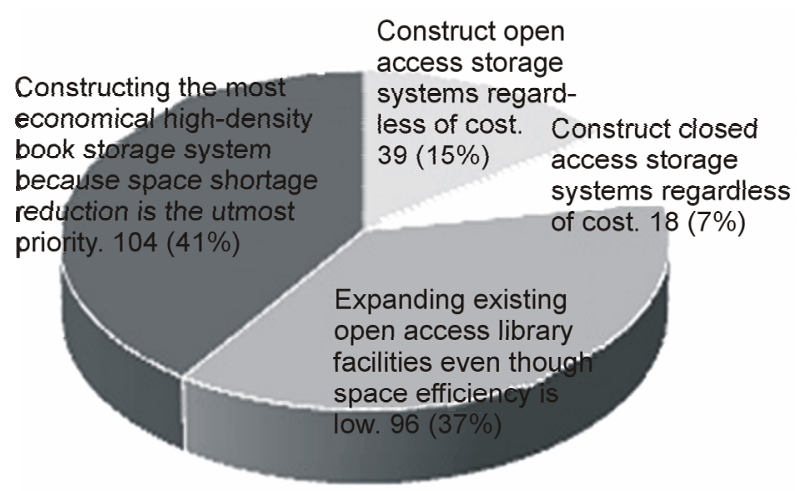

Figure 7. Options for securing extra space for library.

supported the high density storage systems (9\%), resulting in an overall $52 \%$ of votes preferring the open access system compared to the $47 \%$ that preferred the high density storage. It is inferred that the preference for the less efficient system is due to the insufficient understanding of the fairly new concept of high-density book storages. In addition, it can also be inferred that the librarians and other library staff that are under the constant stress of space shortage unquestioningly prefer the open access service because they aren't completely aware of the full import of the issue.

\subsection{If It Were Possible to Transfer 500,000 Books to a New High Density Book Storage, What Would Be the Biggest Benefit to Your Library?}

Improvements to shelving arrangements and operational convenience (52\%) and the addition of a rest area to improve environmental quality (20\%) were the top two potential usages of the new available space acquired from the implementation of the high-density book storage system. The opinions of librarians that believed that benefits brought about by an information commons and learning commons (12\%) were important showed new up and coming trend of considerations for newly available space 
followed by the suggestion to add more reading space and open access shelving (10\%), and adding space for new equipment for academic use (5\%). Figure 8 represents the librarians' opinion on the new available space usage.

Over half of the opinions stating that extra space should be used for better shelving arrangement provide evidence of the librarians' strong will to improve the spatial quality of the library. Furthermore, the other inclination to use space to add more resting areas shows the movement of librarians' ideology of "Library as a Place” [6], showing that economic growth naturally coincides with cultural development.

\subsection{If You Could Not Secure a Budget for an Independent Library Facility, Which Do You Believe Is the Most Practical Plan among the Options Listed below?}

For alternatives for obtaining book storage space, extension of closed access book storages received $39 \%$ of the votes, being the most preferred, followed by utilization of other existing facility (storage, basement, etc.) on campus at $29 \%$, open access book storage extension with $13 \%$; building rent for remote off campus book storages at $3 \%$ was found as a minority opinion. Figure 9 shows the result of this questionnaire survey.

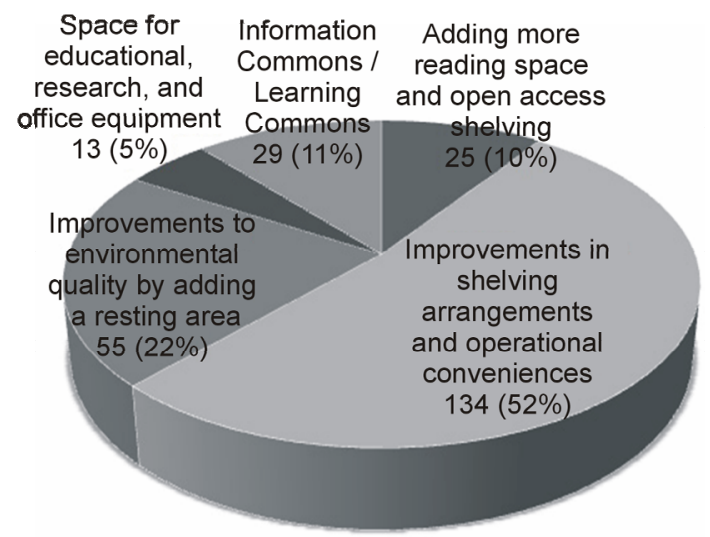

Figure 8. Potential usage of extra space provided by high density book storages.

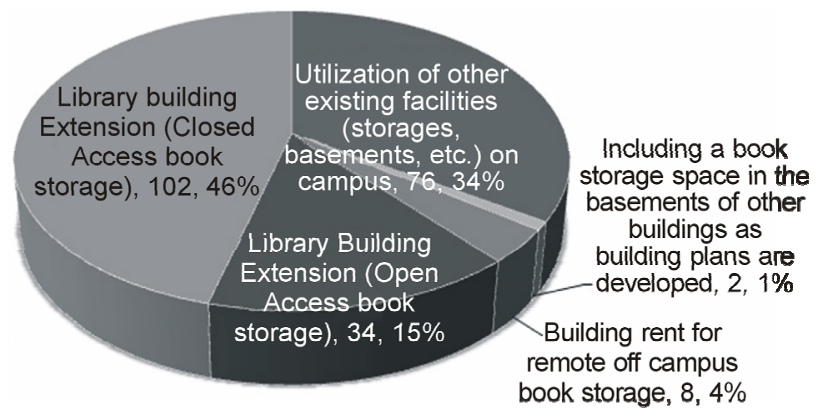

Figure 9. Alternatives to high density book storage.
Librarians showed no preference in including a book storage space in basements of developing buildings, albeit the option would allow for the implementation of a practical plan for maximum usage of real estate while providing a properly designed environment for book storage. It is probable that the idea of a basement brought about an image of a dark and humid environment with deficient ventilation that was negatively perceived as a good space for book storage; it is also possible that the librarians were displeased with the idea of storing books in a location other than a library.

Misconceived by those librarians, this alternative does not conceptualize an environment in which an already existing low quality basement is transformed into book storage. Rather, the option would allow for a new library facility to be constructed underground. If moisture control and appropriate ventilation were implemented, the benefits of an underground facility, including heat and sound insulation quality, protection from direct sunlight, and structural stability, would serve remarkably as book storage. The benefits of a basement facility are currently greatly underappreciated, thus resulting in this particular survey result.

\subsection{What Do You Believe Is the Best Way to Accomplish a Cooperative Storage System in That Universities Come Together to Construct Book Storage under an Economical Budget?}

Table 2 indicates the librarians' preference of the cooperative book storage. Librarians most preferred the cooperative book storage system that implemented joint ownership, joint management (35\%). The options of preserving books together with separate ownership and separate management of a shared storage were voted with similar preferences (23\% and 20\%, respectively). Shared storages being built by the university with funding, but renting out the facility and having the cooperative storage stores and manages its own books without duplicates both resulted in $10 \%$ of the votes. Unique from the other surveys given thus far, this particular questionnaire presented with a tendency to present preferences for all options fairly consistently.

However, as a result of government oversight that induces extreme competitions amongst Korean universities, the goal of joint preservation, joint ownership, and joint management among these educational institutions will be a difficult target to meet. In consequence, joint construction of book storage with independent management will be the most realistic goal for Korean institutions.

\section{Conclusion and Discussion}

As concluded from the results of the full survey, the 
Table 2. Preference of cooperative book storage types.

\begin{tabular}{lc}
\hline Cooperative Book Storage Types & $\begin{array}{c}\text { No. of } \\
\text { Replies } \\
\text { (\%) }\end{array}$ \\
\hline $\begin{array}{l}\text { Under agreement among all the institutions involved, } \\
\text { establish a cooperative storage system under joint } \\
\text { ownership and joint management and work to share } \\
\text { data to preserve only single copies of printed } \\
\text { material. }\end{array}$ & $90(35)$ \\
$\begin{array}{l}\text { The cooperative storage owns and manages the } \\
\text { facility and books independently, preserving single } \\
\text { copies of all printed material }\end{array}$ & $25(10)$ \\
$\begin{array}{l}\text { Under full agreement by the involved institutions, } \\
\text { books are preserved together, but owned separately } \\
\text { by respective universities }\end{array}$ & $57(23)$ \\
$\begin{array}{l}\text { The storage is shared, but managed separately } \\
\text { Book storage is built by institution with funding and } \\
\text { rented or co-managed by other institutions }\end{array}$ & $25(10)$ \\
Total & \\
\hline
\end{tabular}

disuse of high density book facilities such as the Harvard Model that compose of $60 \%$ of American libraries and the overwhelming use of the movable compact shelving (mobile-rack) system by all Korean universities (with the exception of Sungkul University) signify Korean academic librarians' limited knowledge of high density book storage types and storage alternatives.

Considering the outstanding space efficiency and economic feasibility of high-density book storage systems, the questionnaires were returned with somewhat unexpected replies; however, such responses may be rationalized if the librarians answered the surveys with the thought of movable compact shelving in mind because of their lack of understanding of the high-density book storage types. Judging from the inadequate understanding of high-density book storage systems by librarians who are considered experts in the field of library management, it can be said that the public's awareness of such facilities is even more minimal.

Nevertheless, the librarians unanimously adhered to the idea that resolving space shortage problems was their primary priority and in order to meet that goal, facilities must have the outstanding space efficiency. Informing these experts with the strengths and weaknesses of vari- ous book storage types and then reconducting the surveys will ultimately result in meaningful changes to responses. Because there is no record of cooperative storage precedents in Korea, the responses regarding such facilities are seen to have resulted in more notional responses; however, it can be understood that work experience has naturally rooted understanding in our library experts.

This study was conducted to gauge Korean librarians' understanding of high-density book storage facilities widely used for academic and research purposes in highly developed countries and identify reasons why such storage systems were not constructed in Korea. The questionnaire serves as a measure of awareness of librarians on the library space shortage crisis. By analyzing the data retrieved from this survey, we can further work to resolve the space problem in a practical yet meaningful manner.

\section{REFERENCES}

[1] Korean Library Association, "2010 Korean Library Yearbook,” Korean Library Association, Seoul, 2010

[2] J. Ahn, "Space Efficiency Improvement Plan for Academic Library Storage: Focusing on High-Density Storage Facilities” Ph.D. Thesis, Korea University, Seoul, 2011.

[3] H.-J. Yi and Y.-J. Nam, "A Study on the Space Rebuilding Using the Digital Preservation,” Proceedings of the 13th Annual International Conference of the Korean Association of Information Management, Seoul, August 2006, pp. 201-202

[4] J. Ahn, "Study on High-Density Library Storage as a Solution to the Space Shortage Problem: A Case Study of Rice University Library Service Center,” Journal of Korean Institute of Educational Facilities, Vol. 17, No. 6, 2010, pp. 23-30.

[5] L. Payne, "Library Storage Facilities and the Future of Print Collections in North America," OCLA Online Computer Library Center, Inc., Dublin, 2007

[6] K. Antell and D. Engel, "Stimulating Space, Serendipitous Space: Library as Place in the Life of the Scholar," In: J. E. Buschman and G. J. Leckie, Eds., The Library as Place, Libraries Unlimited, Inc., Westport, 2007, pp. 168176. 